ARTIGO

CO https://doi.org/10.22481/praxisedu.v15i36.5912

\title{
HERMENÊUTICA E EDUCAÇÃO: IMPLICAÇÕES A PARTIR DO PENSAMENTO DE HANS-GEORG GADAMER E JÜRGEN HABERMAS
}

\author{
HERMENEUTICS AND EDUCATION: IMPLICATIONS FROM THINKING OF HANS- \\ GEORG GADAMER AND JÜRGEN HABERMAS
}

\begin{abstract}
HERMENEUTICA Y EDUCACIÓN: IMPLICACIONES DEL PENSAMIENTO DE HANSGEORG GADAMER Y JÜRGEN HABERMAS
\end{abstract}

\author{
Anderson de Alencar Menezes \\ Universidade Federal de Alagoas - Brasil
}

Darlan do Nascimento Lourenço

Faculdade São Tomás de Aquino - Brasil

\begin{abstract}
Resumo: o presente texto tem por objetivo apresentar as contribuições do pensamento hermenêutico residente nos postulados teóricos de Hans-Georg Gadamer e Jürgen Habermas. Para tanto, se fará necessário recorrer aos pressupostos basilares que formam a estrutura fundante do pensamento destes dois filósofos, bem como tecer uma articulação crítica entre eles e, posteriormente, trazer para o âmbito educativo como maneira de evidenciar as devidas contribuições para uma formação humana que preze tanto para a compreensão interpretativa quanto para o entendimento entre os sujeitos envolvidos no contexto escolar. Além disso, consideramos que a hermenêutica gadameriana tornou-se uma referência de análise e discussão na contemporaneidade, isto abarcando a educação e o pensamento filosófico. Com a teoria comunicativa habermasiana vimos emergir uma proposta de teoria social atrelada ao uso da linguagem enquanto forma de mediação em interações entre sujeitos numa comunidade de falantes e, neste sentido, seu principal objetivo recai na busca por consensos estabelecidos na forma de entendimentos intersubjetivos. Assim, ao refletir os contributos da teoria hermenêutica gadameriana juntamente com a teoria social habermasiana para os processos educativos, consideramos de vital validez uma vez que partilham da premissa legitimadora da integração entre os indivíduos participantes de um contexto social, seja por meio da tradição ou mesmo pelo diálogo incondicional mediado linguisticamente.
\end{abstract}

Palavras-chave: Educação. Hermenêutica gadameriana. Razão comunicativa habermasiana.

Abstract: The present text aims to present the contributions of hermeneutic thinking residing in the theoretical postulates of Hans-Georg Gadamer and Jürgen Habermas. Therefore, it will be necessary to resort to the basic assumptions that form the founding structure of the thought of these two philosophers, as well as to weave a critical articulation between them and, later, to bring to the educational field as a way of highlighting the proper contributions to a human formation that it values 
both interpretative understanding and understanding among the subjects involved in the school context. Moreover, we consider that Gadamerian hermeneutics has become a reference for analysis and discussion in contemporary times, including education and philosophical thinking. With the Habermasian communicative theory we saw the emergence of a social theory proposal linked to the use of language as a form of mediation in interactions between subjects in a community of speakers and, in this sense, its main objective lies in the search for consensus established in the form of intersubjective understandings. Thus, in reflecting the contributions of Gadamerian hermeneutic theory together with the Habermasian social theory to educational processes, we consider it of vital validity since they share the legitimating premise of integration between individuals participating in a social context, either through tradition or even by unconditional dialogue mediated linguistically.

Keywords: Education. Gadamerian hermeneutics. Habermasian communicative reason.

Resumen: El presente texto tiene como objetivo presentar las contribuciones del pensamiento hermenéutico que residen en los postulados teóricos de Hans-Georg Gadamer y Jürgen Habermas. Por lo tanto, será necesario recurrir a los supuestos básicos que forman la estructura fundacional del pensamiento de estos dos filósofos, así como tejer una articulación crítica entre ellos y, más tarde, llevarlos al campo educativo como una forma de resaltar las contribuciones adecuadas a una formación humana que valora tanto la comprensión interpretativa como la comprensión entre los sujetos involucrados en el contexto escolar. Además, consideramos que la hermenéutica gadameriana se ha convertido en una referencia para el análisis y la discusión en los tiempos contemporáneos, incluida la educación y el pensamiento filosófico. Con la teoría comunicativa habermasiana, vimos el surgimiento de una propuesta de teoría social vinculada al uso del lenguaje como una forma de mediación en las interacciones entre sujetos en una comunidad de hablantes y, en este sentido, su objetivo principal radica en la búsqueda del consenso establecido en forma de entendimientos intersubjetivos. Por lo tanto, al reflejar las contribuciones de la teoría hermenéutica gadameriana junto con la teoría social habermasiana a los procesos educativos, consideramos que tiene una validez vital, ya que comparten la premisa legitimadora de integración entre individuos que participan en un contexto social, ya sea a través de la tradición o incluso por diálogo incondicional mediado lingüísticamente.

Palabras clave: Educación. La hermenéutica gadameriana. Razón comunicativa habermasiana.

\section{Introdução}

A Hermenêutica gadameriana tornou-se uma referência de análise e discussão no âmbito da contemporaneidade. Sobretudo no âmbito das relações educativas e filosóficas em que a importância do pensamento hermenêutico será de grande realce para as temáticas ligadas à fenomenologia e as questões da linguagem.

O fato é que a hermenêutica desde as suas mais remotas origens tenta descortinar uma relação cada vez mais fecunda com os campos filosóficos e educativos. Com raiz de natureza filosófica, procurou desde as teses de uma hermenêutica romântica de Friedrich Schleiermacher (1768-1834) o seu lugar de destaque. O referido autor reconhecia que normalmente ocorrem erros de compreensão, por isso a interpretação é sempre válida. Existia, 
segundo o autor em questão, uma interdependência entre interpretação gramática e a psicológica.

Nesta perspectiva, o nosso objetivo é de lançarmos mão do pensamento hermenêutico de Hans Georg Gadamer (1900-2002) que é um marco fundamental dos temas ligados à linguagem e à fenomenologia. Esta tensão no pensamento gadameriano poderá nos ajudar a entrar num fenômeno da compreensão aplicada ao campo educativo. Nesta perspectiva, reconhecemos a influência heideggeriana e da fenomenologia de Husserl como referências centrais para esta discussão.

Além disso, traremos a proposta de Jürgen Habermas (1929-) no que toca à hermenêutica filosófica para podermos ampliar o debate que cerca os contributos do pensador frankfurtiano e do postulado do autor de Verdade e Método para a esfera educacional. Ademais, a própria estrutura do pensamento habermasiano alicerçado no agir comunicativo enquanto médium, nos servirá de aporte para tal percurso. Neste sentido, far-se-á necessário considerar que a proposta comunicativa habermasiana venha ser uma ponte imprescindível para a reflexão hermenêutica no campo educativo. Uma vez que a validade atribuída à linguagem, na condição de mediadora nos processos envolvendo interações intersubjetivas, poderá legitimar os estados de compreensão, bem como de entendimento no domínio pedagógico.

Como perspectiva metodológica adotamos a pesquisa bibliográfica, que segundo Gil (2002, p. 44) "é desenvolvida com base em material já elaborado, constituído principalmente de livros e artigos científicos. Boa parte dos estudos exploratórios pode ser definido como pesquisa bibliográfica”. Assim sendo, dando substancialidade a presente reflexão envolvendo o debate entre hermenêutica e educação.

\section{A universalidade da hermenêutica em Hans-Georg Gadamer}

Para Gadamer (2002) a Hermenêutica se constitui a partir de sua Universalidade. A tentativa é pensar a hermenêutica em oposição às ciências da natureza. A Hermenêutica gadameriana situa-se num contexto da obra Verdade e Método. Nesta obra, ele irá retomar a perspectiva clássica desde Platão, sobretudo a obra $\mathrm{O}$ Crátilo para repensar as questões da linguagem no âmbito da complexidade que se faz a partir de uma ontologia aberta à presentificação do mundo. Com Platão, no Crátilo, rediscute-se o papel da linguagem enquanto referência fundamental parar interagir com o mundo. Ou seja, rompe-se com a ideia clássica de que 'as palavras designam as coisas' para entrar no âmbito da compreensão de que 
a linguagem adquire sentido no seu uso, ou seja, depende fundamentalmente dos contextos linguísticos que a palavra se insere. Portanto, é de fundamental importância conceber a linguagem numa dimensão mais ampla e complexa.

Gadamer é influenciado pelo pensamento de Heidegger, que postula uma hermenêutica ontológica, fundada no Dasein (ser-aí). A constituição ontológica da linguagem é uma contribuição original de Heidegger para o pensamento gadameriano. Sobretudo, segundo Schmidt $(2012,171)$ "Gadamer, seguindo Heidegger, mantém que a palavra correta 'traz a coisa para a apresentação. Crátilo termina demonstrando que a palavra não é uma cópia, e por isso a única alternativa parece ser que ela é um sinal”.

Neste âmbito de compreensão procura-se a palavra que realmente pertence à coisa. Daí se estabelecer a relação entre a linguagem e o mundo. Foi a partir da concepção de mundo de Heidegger que Gadamer procurou estabelecer a temática da experiência hermenêutica que se caracteriza como evento na linguagem. Desta forma, o intérprete preserva a tradição e aumenta seu efeito. A defesa da Universalidade da hermenêutica em Gadamer está em continuidade com a reabilitação da Tradição. A perspectiva histórica do Iluminismo centrada numa certa compreensão de racionalidade científica tentou refutar o âmbito da Tradição. Gadamer a retoma e a relança a partir de outro olhar. Ou seja, na tradição se constitui a nossa historicidade e a nossa linguagem enquanto arremessados no mundo, na perspectiva heideggeriana. Neste sentido, o fato de estarmos 'jogados no mundo' encerra uma nova compreensão da nossa interpretação de nós mesmos e no mundo circundante. Para compreender é preciso estar mergulhado no mundo, embebido pelas suas facticidades. Só compreendemos a partir desta inserção radical no mundo. Daí a ideia da Universalidade da Hermenêutica gadameriana, ou seja, preciso estar radicalmente no mundo para interpretá-lo, já que toda forma de compreensão já é uma interpretação.

De acordo com Grondin (2012, p.76):

Todo pensamento já é busca de linguagem. Não existe pensamento sem linguagem. Mas aqui se trata de uma evidência que o pensamento ocidental teria teimado em menosprezar desde Platão, ao atribuir à linguagem um estatuto segundo em comparação com o pensamento autônomo. Aqui, Gadamer denuncia um esquecimento da linguagem que teria atravessado toda a nossa tradição ocidental e à qual ele só conhece uma exceção: a ideia, entrevista por Agostinho, de uma 'identidade de essência' fundamental entre o pensamento (o logos) e sua manifestação linguística (sua encarnação). 


\section{O problema da compreensão hermenêutica: relações entre Historicidade e Linguagem}

$\mathrm{Na}$ esteira de Hermann (2002) a descoberta da pré-estrutura ou círculo da compreensão desloca a compreensão para a temporalidade do Dasein (ser-aí). Ou seja, será preciso pensar que o horizonte interpretativo pode ser e deve ser transcendido pelos intérpretes. Já que uma dada subjetividade transcendental dá lugar a uma relação efetual com a história e com a linguagem. Neste sentido, rompe-se com uma subjetividade transcendental fundada na intencionalidade da própria consciência, daqui a crítica a Husserl e depois uma crítica a uma espécie de história absoluta em Hegel. A relação da metafísica clássica entre sujeito cognoscente e objeto cognoscível é suplantada pela historicidade dos sujeitos interpretantes mediatizados pela historicidade que os atravessa enquanto seres lançados e arremessados no mundo.

Neste âmbito de compreensão, toda a nossa forma de compreensão é embevecida por pressupostos e preconceitos. Gadamer retoma da Tradição a ideia de preconceito e o reabilita. Na sua compreensão há preconceitos legítimos e preconceitos não legítimos. Herdamos da Tradição estruturas prévias de compreensão que precisam ser expostas ao exame de todos os participantes. O preconceito legítimo procura dizer a verdade que pertence à coisa mesma, fora disto, o que há são preconceitos ilegítimos. Segundo Gadamer (2002, p.406):

Portanto, não se trata, de modo algum, de assegurar-se a si mesmo contra a tradição que faz ouvir sua voz a partir do texto, mas, pelo contrário, de manter afastado o que possa impedir alguém de compreendê-la a partir da própria coisa. São os preconceitos não percebidos os que, com seu domínio, nos tornam surdos para a coisa de nos fala a tradição.

A pré-compreensão e a historicidade são pressupostos fundamentais para a interpretação, já que a compreensão é um fenômeno. Gadamer parte da estrutura circular da compreensão de Heidegger para pensar que a compreensão do ser não é a compreensão do objeto. Daí que a conclusão é de que não são os juízos, mas os pré-juízos que constituem nosso ser.

De uma forma aberta Gadamer rompe com a tradição Iluminista de compreensão, que durante alguns séculos se opuseram à postura romântica da compreensão. Pois, o Iluminismo sempre atribuiu ao preconceito uma conotação negativa. Nesta perspectiva, na compreensão opera-se sempre uma tensão entre familiaridade e estranheza. 


\section{Hermenêutica e educação: implicações gadamerianas}

Um dos aspectos fundamentais da hermenêutica gadameriana é pensar a partir do círculo hermenêutico como uma relação intensamente criadora. As relações entre os horizontes do autor, do texto e do intérprete são fecundas por horizontes que precisam ser fundidos para que a compreensão de fato aconteça. A partir do horizonte do intérprete percebe-se a natureza de uma interpretação estendida, arremessada.

As implicações da hermenêutica gadameriana para os processos educativos podem ser pensados a partir de quatro aspectos fundamentais. O primeiro aspecto é romper com a visão das ciências naturais de um espírito objetivador, que objetiva cercear os traços da historicidade, os apelos que advêm da tradição, ou seja, as perguntas que tradição nos faz. Neste sentido, a educação passaria por um reabilitar a historicidade como lugar por excelência do acontecimento hermenêutico. Um segundo aspecto diz respeito ao diálogo como espaço de compreensão mútua. Neste sentido, Gadamer compreendeu o diálogo a partir de uma densidade semântica muito interessante. Em Verdade e Método II ele apresenta a incapacidade para o diálogo. O diálogo autêntico supõe o reconhecimento de que pertencemos a uma tradição, neste sentido, que estamos vinculados por um horizonte que nos transcende e nos impele para uma complexidade maior entre o "eu" e o mundo. O diálogo supõe que não sei ainda da resposta, que não quero demarcar minha posição. Reitera Gadamer (2002, p.559),“só podemos aprender pelo diálogo.”

Um terceiro aspecto fundamental que emerge desta relação é a tentativa de recuperar a temática da Formação. É aqui que converge e se distingue as relações entre familiaridade e estranheza. A experiência da compreensão acontece nesta relação dialética. Sobretudo ao se inscrever na ideia de que a compreensão como fenômeno nos remete para a importância de se reconhecer a alteridade.

Um quarto aspecto e último é a importância vital da linguagem para o giro hermenêutico gadameriano e para a educação. Pois, através da linguagem nos reconhecemos pertencentes a uma tradição que nos interroga e nos interpela. Somos atravessados pela historicidade. Pensar que no âmbito gadameriano pensamento e linguagem se constituem profundamente. Para o âmbito educativo isto nos faz pensar que as nossas relações educativas são marcadas pelo universo da linguagem não como meio ou instrumento, mas como nos diz Gadamer (2002, p.680) “o ser que pode ser compreendido é linguagem”, ou seja, ele desenvolve uma ontologia linguística em oposição a uma interpretação antropocêntrica da linguagem, que a reduz a um mero instrumento do pensamento (HERMANN, 2002). Neste 
âmbito de compreensão, a nossa tarefa educativa primordial no âmbito educativo é ajudar a todos os envolvidos nas relações educativas a procurarem a palavra que diz a coisa mesma. Sem instrumentalizações ou artificialismos.

\section{Jürgen Habermas e o resgate dos preceitos normativos da modernidade}

Ao elaborar seu projeto filosófico, Habermas muito será influenciado pelas experiências vividas durante os anos de filiação no Instituto de Pesquisas Sociais de Frankfurt, posteriormente denominada Escola de Frankfurt. Sobretudo mediante o contato com as obras dos notáveis pensadores dali. É o caso dos trabalhos de Adorno e Horkheimer, principalmente. Entretanto, não podemos dizer seguramente que o autor da razão comunicativa seja herdeiro das premissas teóricas destes pensadores, uma vez que rompe com os seus postulados.

É justo afirmar, por conseguinte, que Habermas (2012a; 2012b) muito além de entusiasta, é um defensor do projeto emancipador iluminista que orientaria o homem guiandoo através da razão. Neste sentido, o autor alemão faz-se unânime em afirmar que o projeto moderno encontra-se inacabado e não esgotado, como previram os filósofos do século $\mathrm{XX}$, denominados Pós-modernos ${ }^{1}$.

Essa perspectiva iluminista fundada na razão e trazida a primeiro plano pelo pensamento habermasiano estará presente no desenvolvimento de todo o seu escopo intelectual. Neste sentido, o debate em torno do saber hermenêutico não estaria isento.

Entretanto, para propor a retomada da diretriz iluminista enquanto meio para viabilizar o projeto da razão comunicativa, Habermas entende a necessidade de trazer à discussão as categorias de Modernidade e Racionalidade. É por meio da compreensão que envolve estas categorias que poderemos melhor empreender a maneira como se pôde solidificar a proposta teórica habermasiana.

A Modernidade, de acordo com Habermas (2000, p. 01), "foi elevada, desde os fins do século XVIII, a tema filosófico". E, neste quesito, o autor irá se preocupar em recuperar os preceitos normativos desta, resgatando "o projeto Iluminista original, mantendo o espírito e modificando a forma" (FREITAG, 2005, p. 186).

\footnotetext{
${ }^{1}$ Referência feita ao conjunto de filósofos do século XX que defendiam o esgotamento da razão enquanto meio orientador para atingir a garantia de compreensão da realidade e do mundo. Ganha destaque, sobretudo, o filósofo francês Jean-François Lyotard (1924-1998) e a obra de sua autoria A Condição Pós-moderna de 1979.
} 
Nesse sentido, a modernidade se coloca enquanto uma reviravolta no modo de se interpretar a realidade, especialmente no tocante ao espírito e as concepções medievais, atreladas à religião e ao mito. Quer dizer, substitui-se o postulado que até então se mantinha soberano e dogmático (BOLZAN, 2002), por outro que, fincado na possibilidade de um sujeito de razão autônoma, podendo este utilizá-la como instrumento e lançar-se sobre a natureza tornando-a seu objeto de conhecimento.

Diante disso, a razão é responsável por representar o mundo a partir do momento que apreende a realidade transformando-a em conceito. O cogito cartesiano, por conseguinte, é encarregado de garantir a verdade absoluta e marca o ponto inicial da filosofia moderna. $\mathrm{O}$ postulado cartesiano: "penso, logo existo!" afirma, definitivamente, não apenas a centralidade do conhecimento nas mãos do homem moderno, mas assegura o domínio mesmo que metafísico sobre a realidade objetiva do mundo.

Na verdade, esse pressuposto antropológico que Descartes (2008) inaugura e o período moderno reproduz colabora, efetivamente, para afirmar a centralidade da subjetividade do sujeito. Onde antes o homem se colocava enquanto mero expectador do mundo; agora, através da capacidade que possui de uma racionalidade questionadora, encara-se como um ser apto em condições de compreender tudo à sua volta.

Em todo caso, a nova mentalidade do homem fundamentada no pressuposto da subjetividade, colaborará para o desenvolvimento tanto do novo cenário histórico, quanto trará profundas mudanças no que se entendia por conhecimento filosófico e científico. Visto que "o princípio da subjetividade determina as manifestações da cultura moderna. [...] isso vale para a ciência objetivante que, ao mesmo tempo, desencanta a natureza e liberta o sujeito cognoscente" (HABERMAS, 2000, p. 26). E aqui reside a crítica habermasiana aos processos de racionalização do mundo.

Convém referir que a formação do homem sob a base humanista iluminista moderna representou uma grande reviravolta no ato de conhecer também. A prevalência da subjetividade e de uma razão enquanto consciência de si, autorreferente e autossuficiente transformada em uma teoria da consciência, proporcionou um rompimento significativo com os postulados filosóficos do passado; mas abriu, consequentemente, um abismo no que diz respeito aos modos de reprodução social. Principalmente devido à nova constituição econômica, política e social que ganhava mais evidência durante o período. Sendo assim, “a racionalidade única do iluminismo, do esclarecimento, que em sua arquitetura original tinha por finalidade libertar o ser humano, transformou-se em uma nova forma de dominação" (TREVISAN, 2000, p. 82-3). 
Impressionante é a pretensa convicção no potencial de progresso humano baseado numa formação através de uma ciência metódica para a edificação de uma sociedade mais desenvolvida. Contudo, as formas de conhecimento provenientes desta formação positiva se mostraram não apenas específica e dominadora ao extremo, mas também com interesses bem situados. Tal qual a ênfase dada às necessidades impostas pelo sistema capitalista industrial que causou uma verdadeira guinada no modo de reprodução social com a promessa de progresso aos indivíduos mais bem adaptados a este cenário. Quer dizer, a crença que se faz eminente neste momento é aquela residente na prevalência de estruturas epistemológicas que deem subsídio a consecução de atividades cujas finalidades residam na manutenção do próprio sistema vigente e não propriamente no potencial intelectivo e emancipador do indivíduo.

O controle rigoroso na formação para atingir contínuo desenvolvimento da sociedade visando atender as necessidades do mercado capitalista industrial, torna-se determinantemente crucial dos tempos modernos. Em outras palavras, "a racionalização burocrática se constitui numa postura organizacional da ação que se impõe com o avanço do capitalismo, e com suas exigências de produção e eficiência" (BOLZAN, 2005, p.32).

De fato, essa racionalização provoca uma reviravolta no modo como será aplicada a formação dos indivíduos na sociedade. Ora, como forma de atender as necessidades constatadas a partir de todo o conglomerado industrial recente, se torna urgente a formação de sujeitos qualificados para desenvolverem atividades que requeiram maior controle e eficiência, isto é, uma formação especializada. Neste sentido, garantindo maior produtividade e competição. Ou, “a concepção moderna de educação, esboçada a partir do modelo social hegemônico está comprometida com a organização racional do trabalho, com as inovações tecnológicas e com a organização da sociedade estabelecida a partir da exploração econômica" (TREVISAN, 2000, p. 71).

Dada à reflexão suscitada acima, é justo considerar que a racionalidade subjetiva predominante no projeto moderno trouxe uma série de distúrbios sociais. Habermas (2012a), nesse quesito, procura desenvolver no seu intento reconstrutivo ${ }^{2}$, uma nova compreensão acerca do quadro procurando demonstrar que é indissociável a noção de modernidade sem que haja direta menção a racionalização técnico-instrumental.

\footnotetext{
${ }^{2}$ Método utilizado pelo autor para, a partir de uma revisão crítica e sistemática em torno de uma teoria, poder remontá-la de tal modo que sua tese central seja restabelecida de acordo com a finalidade original que ela se propôs inicialmente. Nas palavras de Habermas (2016, p. 25), "Reconstrução, em nosso contexto, significa que uma teoria é decomposta e recomposta em uma nova forma para que possa atingir o fim que ela mesma se pôs: esse é um modo normal... de se relacionar com uma teoria que, sob diversos aspectos, precisa de revisão, mas cujo potencial de estímulo (ainda) não se esgotou".
} 


\section{A reviravolta linguística da filosofia como pano de fundo da teoria comunicativa habermasiana}

De outro modo, Habermas (2012a; 2012b) concebe a necessária restauração da razão emancipadora humana prevista na modernidade através da adoção do modelo intersubjetivocomunicativo. A elaboração por parte do filósofo alemão desta teoria social, como costuma se referir, se deu através da adoção das recentes teorias da filosofia da linguagem que surgiram no início do século XX. Movimento este que ficou conhecido como giro linguístico (linguistic turn).

Essa ruptura promovida pela reviravolta pragmática possibilitou ainda uma nova percepção na maneira de conduzir os questionamentos em torno do conhecimento humano. Tal é que, substituída a centralidade acerca da natureza, causa e condições do conhecimento pelo sujeito, lança-se a suposição sobre o sentido e possibilidades de sentenças intersubjetivamente válidas referente à realidade (MUHL, 2003). Neste ponto, o valor atribuído à necessidade de evidenciar o uso linguístico configura sua validade diante dos sentidos compartilhados com outros indivíduos através do conhecimento estabelecido na ação linguística instituída reciprocamente no mundo. Ou seja, "a linguagem torna-se o espaço da expressividade do mundo, a instância de articulação de sua inteligibilidade" (idem, p. 171).

Nessa dinâmica emerge, portanto, a prevalência de uma filosofia centrada no modelo de racionalidade que valorize a busca por entendimento intersubjetivo de atores sociais em interação. De acordo com isso, o lugar que a razão comunicativa assumirá de destaque no mundo social terá efeitos nunca antes previstos, uma vez que o programa habermasiano propõe o rompimento imediato com formas de conhecimento provenientes da orientação técnico-instrumental oriundas da filosofia do sujeito, certo de que estas promovem situações que suas formas reprodutivas são antinomias a sua tese comunicativa.

Considerando que a razão proposta por Habermas está situada no domínio pragmático da filosofia, o desmanche centralizador e totalizador do modelo da filosofia do sujeito tornouse indubitável. Com efeito, essa guinada pragmática possibilita a inserção de um horizonte novo de implicações e significações provenientes da capacidade de ação no mundo pelos sujeitos. Não obstante, o que satisfaz o modelo da racionalidade comunicativa, por conseguinte, é a total participação no mundo que os atores sociais possam ter. Do mesmo modo, “o mundo só conquista objetividade ao tornar-se válido enquanto mundo único para uma comunidade de sujeitos capazes de agir e utilizar a linguagem" (HABERMAS, 2012a, p. 40 - grifos do autor). 
É claro que a evidência em torno da racionalização de base comunicativa situa-se naquilo que é o pressuposto fundamental para os sujeitos diante da ótica habermasiana, isto é, o entendimento (Verständigung). Indivíduos capazes de manterem entre si relações que visem um ponto comum estabelecido a partir do melhor argumento apresentado, questionado e aceito como válido pelos demais na comunidade, reflete a convicção que a disputa linguística racionalmente mediada alcançou seu propósito. Isto é, fora exercida na ocasião uma racionalidade comunicativa entre todos os participantes, de modo que seus comportamentos foram orientados por esta resultando no consenso mútuo entre todos. Uma vez que, "o conceito de entendimento remete a um comum acordo almejado pelos participantes e racionalmente motivado, que se mede segundo pretensões de validade criticáveis" (IBIDEM, p. 147).

Ora, a abertura dada para todos os envolvidos no diálogo em que suas críticas possam encaminhar ao melhor argumento exposto e defendido, sendo este considerado uma premissa admissível, é consequência clara de um processo de racionalização dialógica que contempla todos os indivíduos que se propuseram ao debate e, não produto de uma razão isolada do mundo que a tudo controla e impõe sua vontade. De certo, a autoridade que a razão comunicativa motivada ao entendimento conserva, julga Habermas, deve preponderar sobre formas que desconsiderem um contexto amplo de sentidos inscritos para os sujeitos no mundo.

Desse modo, a expansão das possibilidades de conhecimento em que as relações interpessoais possam se estabelecer socialmente válidas, dentro do contexto comunicacional, abre também novos cenários para a atuação dos atores sociais. Quer dizer, pela compreensão simbólica comunicativa do mundo, são desencadeadas novas estruturas reprodutivas no que diz respeito aos modos que o sujeito lida consigo, com os demais e com o mundo propriamente dito enquanto espaço culturalmente estabelecido. Em outras palavras,

Habermas estabelece um entrelaçamento entre a compreensão de mundo, os
conceitos de ação e os processos de reprodução desencadeados pela busca do
conhecimento. A ação comunicativa abrange, a um só tempo, a interpretação
do saber cultural, os processos de interação social e de socialização e a
constituição da própria identidade. (LIMA, 2003, p. 85)

Evidentemente, a principal motivação do pensamento habermasiano, através de suas variadas obras, reside na postura de buscar reabilitar a natureza emancipadora da razão. Recordemos, que o projeto habermasiano está fundado no uso comunicativo da razão entre participantes de um debate livre de coação. Ou seja, numa comunidade de atores sociais aptos 
a manterem entre si laços discursivos em que o uso social da linguagem argumentativa poderá mediatizar as relações interpessoais entre estes. Além do que, poderá servir de afirmação da identidade autônoma de cada sujeito participante do contexto comunicativo encaminhando, consequentemente, a possibilidade do reconhecimento da figura do outro no processo dialogal.

Indo além, a Teoria da Ação Comunicativa representa, para o autor, uma nova maneira de caracterizar a realidade a partir da validação e reconhecimento das múltiplas vozes na sociedade. Isso equivale dizer que, na teoria comunicativa habermasiana, serão adotadas formas positivas de certificação de identidades subjetivas segundo as premissas de ordem intersubjetivamente estabelecidas no mundo da vida, bem como inscritas nas personalidades dos próprios indivíduos. Tal que, "os sujeitos que agem comunicativamente estão situados em um mundo da vida o qual, de um lado, viabiliza as ações comunicativas por eles; e, de outro lado, mantém-se pelo próprio processo de entendimento" (VASCONCELOS, 2017, p. 38).

Habermas (2012b) fixa, neste sentido, o conceito de mundo da vida (Lebenswelt) interligado ao contexto linguístico inscrito em uma práxis comunicativa, em que o transcurso deste estabelecerá a via do entendimento através da fala. Constitui-se, também, como o lugar referencialmente estabelecido através de um conjunto pré-determinado e pré-constituído de sentidos que darão possibilidades a ação comunicativa. Além disso, representa a instância em que serão transmitidos os saberes culturais de uma dada sociedade de indivíduos de modo interpessoal. E, nesse sentido, a ideia de mundo da vida se estabelece enquanto cenário primordial da validez do paradigma intersubjetivo. Por esse viés,

O mundo da vida constitui, pois, de certa forma, o lugar transcendental em que os falantes e ouvintes se encontram; onde podem levantar, uns em relação aos outros, a pretensão de que suas exteriorizações condizem com o mundo objetivo, social ou subjetivo; e onde podem criticar ou confirmar tais pretensões de validade, resolver seu dissenso e obter consenso. (2012b, p. 231)

O mundo da vida se apresenta, portanto, como o lugar onde é possível se estabelecer experiências de ordem intersubjetiva sem, no entanto, ferir a subjetividade de outro sujeito participante da interação. Quer dizer, como espaço que viabiliza o agir comunicativo. E este se mostra também possibilitador de novas experiências através das vivências compartilhadas mutuamente, em que serão validadas as manifestações de atores sociais com capacidade de externar o mundo através do ato simbólico de projetar a realidade por meio da linguagem. 


\section{Habermas e a hermenêutica do entendimento}

Habermas ao promover seu projeto reconstrutivo, o fez tendo que atravessar uma imensidade de áreas do conhecimento e, entre elas, as ciências interpretativas. Partindo desde W. von Humboldt (1767-1835) a Dilthey (1833-1911), de Heidegger (1889-1976) a Gadamer (1900-2002). Contudo, a real intenção do autor não era, a vista disso, estabelecer uma genealogia ou historiografia da hermenêutica filosófica simplesmente. Mas, buscar estabelecer a possibilidade dessa forma de conhecimento ser capaz de compreender a realidade do mundo muito além do intérprete, mas envolvendo também a tradição e a razão (MENEZES; LIMA, 2016).

Em torno disso, a compreensão habermasiana da hermenêutica filosófica, situa-se ao afirmar que:

[...] A hermenêutica filosófica, de sua parte, investiga a competência interpretativa de falantes adultos sob o aspecto da maneira pela qual um sujeito apto a falar e agir, imerso em um ambiente estranho, trata de tornar exteriorizações incompreensíveis compreensíveis para si. A hermenêutica ocupa-se com a interpretação enquanto realização excepcional que só se torna obrigatória quando recortes relevantes do mundo da vida passam a ser problemáticos, quando no plano de base culturalmente internalizado desmoronam algumas certezas e quando fracassam os recursos normais do entendimento. (2012a, p. 243-244 - Grifos do autor)

A possibilidade do exercício hermenêutico representar a ocasião pela qual são lançados meios interpretativos dotados de condições de "aclarar" o que está "nebuloso", é possível perceber que nosso autor se coloca na posição de trazer para o exercício interpretativo o potencial que a linguagem possui como médium consensual. Em outras palavras, "interpretar é compreender em meio à linguagem, os valores reais que buscam sustentar a relação entre as normas das coisas e o estado das coisas" (MENEZES; LIMA, 2016, p. 49).

Habermas adota essa postura para mais uma vez reafirmar o potencial que a intersubjetividade possui na sua teoria social. Isto é, apoiado em relações linguisticamente mediadas, o saber hermenêutico se estabelece enquanto possibilidade orientadora da ação que visa ao entendimento entre os participantes de uma interação. Aqui, destacamos a capacidade que falantes têm em emitir uma sentença racionalmente construída que será recebida por um ouvinte, criticada, e possivelmente aceita como válida. Outra vez, portanto, o percurso desenvolvido por Habermas se faz na medida em que a ação comunicativa, mesmo 
hermeneuticamente, seja resultado de uma interação estabelecida intersubjetivamente. Tal que, "no enfoque hermenêutico há o descentramento da razão do sujeito para a linguagem. [...] a linguagem é mediadora da intersubjetividade e, portanto, mediadora de entendimento sobre algo, buscando consensos mínimos a respeito do conhecimento da realidade" (MARTINAZZO, 2005, p.104).

Isso faz com que os processos interpretativos deem possibilidade para os sujeitos interagirem no mundo situados em uma dada comunidade de falantes capazes de entenderemse entre si e o resultado desse consenso mútuo sirva para todos enquanto compreensão de interações simbolicamente mediadas (COUTINHO, 2002).

Não obstante, sobre esse propósito, Habermas tece a seguinte consideração:

Em comunicações cotidianas, uma exteriorização nunca está lá por si mesma; acrescenta-se a ela a partir do contexto um teor de significado cuja compreensão o falante pressupõe no ouvinte. Também o intérprete tem de introduzir-se nesse nexo de referências como parceiro participativo na interação. O momento explorativo, voltado ao conhecimento, não se deixa desvincular do momento criativo, orientado a que se alcance um consenso. Pois o intérprete não pode alcançar a pré-compreensão de uma exteriorização nele situada, se não participa do processo de formação e avanço desse contexto. (2012a, p. 234-235)

Nessa perspectiva, o pensamento hermenêutico em Habermas assume uma postura fixada diante de um agir orientado linguisticamente ao entendimento dos participantes na interação. Consideremos, por esta via, que a abertura para a viabilidade de um projeto educacional fixado em torno dessa capacidade de que tanto a formação, quanto o conhecimento provenientes do processo educativo, se dê apoiado nessa premissa intersubjetiva; e que o resultado proveniente dessa relação seja o devido reconhecimento de realidades compartilhadas de maneira equivalente entre todos os membros da comunidade educativa.

Indo mais além, ao adotar a postura de uma hermenêutica comunicativa para a educação sob o viés habermasiano, é possível considerar também, que a validade atribuída no processo interpretativo da realidade do sujeito educativo consolide a própria ideia de retomar uma formação emancipadora, tal qual o modelo normativo da modernidade e que Habermas busca restaurar. Isto é, a validade dada ao potencial interpretativo de um ator social, compartilhado e aceito pelos demais membros da comunidade dará plena convicção de que o movimento em direção ao entendimento se deu. E, neste sentido, o caráter próprio da educação voltada para a construção de identidades individuais firmadas em torno da autonomia do sujeito poderá ser evidenciada intersubjetivamente. Certo de que, "a perspectiva 
habermasiana, ao pensar uma hermenêutica reconstrutiva repensa o papel do intérprete a partir de uma atitude [...] performativa que propõe o uso cooperativo da linguagem, ou seja, a utilização do discurso para fins de entendimento recíproco" (MENEZES; LIMA, 2016, p. 54).

\section{Considerações Finais}

Pensar em continuidade com Gadamer é algo extremamente criador. Sobretudo pelas suas preocupações muito genuínas e atuais. A sua pretensão é tentar desconstruir que as verdades científicas são oriundas exclusivamente das ciências naturais que se construíram narrativas ao longo da história sobre os lugares originários para o desenvolvimento do pensamento científico. A aposta numa racionalidade científica que desprezou os apelos vindos da tradição, da história e por consequência do universo da linguagem foi algo que motivou Gadamer a postular outras formas de cientificidade não mais fundadas num certo racionalismo científico dedutivo e hipotético. Sobretudo ao tentar romper com a posição iluminista que cria o mundo dos experts em detrimento do mundo da vida. A proposta gadameriana é de sermos intérpretes qualificados da experiência humana. Justamente neste ponto fundamental, nos tornamos a pergunta fundamental cujo acesso privilegiado se concede à historicidade e à linguagem.

Ao mesmo tempo em que procuramos situar mediante a premissa reconstrutiva habermasiana enquanto possibilidade plenamente factível de empreender uma construção da ação educativa firmada em torno de uma hermenêutica do entendimento; procuramos refletir, esse novo agir educacional envolto em um âmbito emancipador. Assim, poderemos conceber que os contributos derivados da teoria da ação comunicativa de Habermas enquanto teoria da sociedade, como assim pressupõe o autor, poderão trazer significativos estímulos a uma educação escolar cujo princípio de formação humana esteja envolvida no ideal de autonomia do sujeito.

Por estas perspectivas, a aproximação das premissas teóricas de Gadamer e de Habermas partilhadas acima, no intuito de produzir uma reflexão que encaminhe novos rumos para a educação, é considerar possível criar atualizadas formas de lidar com a compreensão da realidade e da interação entre os indivíduos inscritos no contexto escolar, bem como criar formas integradas de entendimento interpessoais. 


\section{REFERÊNCIAS}

BOLZAN, José. Habermas: razão e racionalização. Ijuí: Ed. Unijuí, 2005.

COUTINHO, Maria de Sousa Pereira. Racionalidade comunicativa e humano em Jürgen Habermas: bases de um pensamento educacional. Lisboa - PT: Edições Colibri, 2002.

DESCARTES, René. Discurso do método. Petrópolis, RJ: Vozes, 2008. (Coleção textos filosóficos)

FREITAG, Bárbara. Dialogando com Jürgen Habermas. Rio de Janeiro: Tempo Brasileiro, 2005.

GADAMER, Hans-Georg. Verdade e Método. Petrópolis: Vozes, 2002.

GIL, Antonio Carlos. Como Elaborar Projetos de Pesquisa. São Paulo: Editora Atlas, 2002.

GRONDIN, Jean. Hermenêutica. São Paulo: Parábola Editorial, 2012.

HABERMAS, Jürgen. O Discurso filosófico da modernidade / Jürgen Habermas; tradução: Luiz Sérgio Repa, Rodnei Nascimento. - São Paulo : Martins Fontes, 2000.

Teoria do agir comunicativo, 1: racionalidade da ação e racionalização social / Jürgen Habermas; tradução Paulo Astor Soethe; revisão da tradução Flávio Beno Siebeneichler. - São Paulo: Editora WMF Martins Fontes, 2012a.

Teoria do agir comunicativo, 2: sobre a crítica da razão funcionalista / Jürgen Habermas; tradução Flávio Beno Siebeneichler. - São Paulo: Editora WMF Martins Fontes, 2012b.

Para a Reconstrução do Materialismo Histórico. Tradução de Rúrion Melo. - $1^{\mathrm{a}}$ ed. - São Paulo: Editora Unesp, 2016.

HERMANN, Nadja. Hermenêutica e Educação. Rio de Janeiro: DP\&A, 2002.

LIMA, João Francisco Lopes de. A Reconstrução da tarefa educativa: uma alternativa para a crise e a desesperança. Porto Alegre: Mediação, 2003.

MARTINAZZO, Carlos. Pedagogia do entendimento intersubjetivo: razões e perspectivas para uma racionalidade comunicativa na pedagogia. Ijuí. Ed. UNIJUÍ, 2005.

MENEZES, Anderson de Alencar; LIMA, José Aparecido de Oliveira. A "Consciência" Hermenêutica em Habermas: Interfaces e Diálogos. ÁGORA FILOSÓFICA. Ano 16, $\mathrm{n}^{\circ} .3$ (especial) jul/dez. UNICAP: PE, 2016, pp. 48-55. Disponível em:

http://www.unicap.br/ojs/index.php/agora/article/view/866. Acesso em 11/05/2019.

MUHL, Eldon Henrique. Habermas e a educação: ação pedagógica como agir comunicativo. Passo Fundo: UPF, 2003. 
RAMOS, Antonio Gómez (Org). El ser que puede ser comprendido es lenguaje: homenaje a Hans-Georg Gadamer. Madrid: Editorial Síntesis, 2001.

SCHIMIDT, Lawrence. Hermenêutica. Petrópolis: Vozes, 2012.

TREVISAN, Amarildo L. Filosofia da educação: mímesis e razão comunicativa. Ujuí: UNIJUÍ, 2000.

VASCONCELOS, Francisco Antonio de. Algumas contribuições de Habermas para a educação. 1. ed. Curitiba: Appris, 2017.

\section{SOBRE OS AUTORES:}

\section{Anderson de Alencar Menezes}

Doutor em Ciências da Educação pela Universidade do Porto/Portugal. Professor Adjunto da Universidade Federal de Alagoas (UFAL). Membro do Conselho Editorial e Consultor da revista REDUC( Revista Eletrônica de Educação de Alagoas). Professor e pesquisador do mestrado e doutorado em educação do PPGE/CEDU/UFAL. Líder do Grupo de Pesquisa Teoria Crítica, Emancipação e Reconhecimento - TeCER, filiado ao Programa de Pósgraduação em Educação da UFAL. E-mail: anderufal@gmail.com

(iD) http://orcid.org/0000-0003-4785-2289

\section{Darlan do Nascimento Lourenço}

Mestre em Educação Brasileira pelo Programa de Pós-graduação em Educação da Universidade Federal de Alagoas (UFAL). Professor e Coordenador do Curso de Licenciatura em Filosofia da Faculdade São Tomás de Aquino (FACESTA). Membro do Grupo de Pesquisa Teoria Crítica, Emancipação e Reconhecimento - TeCER, filiado ao Programa de Pós-graduação em Educação da UFAL. E-mail: darlan.nlourenco@gmail.com

(iD http://orcid.org/0000-0002-3151-7980

Recebido em: 12 de outubro de 2018 Aprovado em: 08 de dezembro de 2018 Publicado em: 04 de dezembro de 2019 